\title{
Investigation of DDT resistance mechanisms in Anopheles funestus populations from northern and southern Benin reveals a key role of the GSTe2 gene
}

\author{
Genevieve M. Tchigossou ${ }^{1,2}$, Seun M. Atoyebi ${ }^{3}$, Romaric Akoton ${ }^{1,2}$, Eric Tossou ${ }^{1,2}$, Djegbe Innocent ${ }^{4}$,
} Jacob Riveron ${ }^{5}$, Helen Irving ${ }^{5}$, Akadiri Yessoufou' ${ }^{1}$, Charles Wondji ${ }^{5,6}$ and Rousseau Djouaka ${ }^{1 *}$ (1)

\begin{abstract}
Background: Understanding the molecular basis of insecticide resistance in mosquito, such as Anopheles funestus, is an important step in developing strategies to mitigate the resistance problem. This study aims to assess the role of the GSTe2 gene in DDT resistance and determine the genetic diversity of this gene in An. funestus.

Methods: Gene expression analysis was performed using microarrays and PCR while the potential mutation associated with resistance was determined using sequencing.

Results: Low expression level of GSTe2 gene was recorded in Burkina-Faso samples with a fold change of 3.3 while high expression (FC 35.6) was recorded in southern Benin in Pahou (FC 35.6) and Kpome (FC 13.3). The sequencing of GSTe2 gene in six localities showed that L119F-GSTe2 mutation is almost getting fixed in highly DDT-resistant Benin (Pahou, Kpome, Doukonta) and Nigeria (Akaka Remo) mosquitoes with a low mutation rate observed in Tanongou (Benin) and Burkina-Faso mosquitoes.
\end{abstract}

Conclusion: This study shows the key role of the GSTe2 gene in DDT resistant An. funestus in Benin. Polymorphism analysis of this gene across Benin revealed possible barriers to gene flow, which could impact the design and implementation of resistance management strategies in the country.

Keywords: Anopheles funestus, Mechanism of resistance, DDT, GSTe2, Benin

\section{Background}

Malaria remains the most severe infectious disease and a major public health challenge in sub-Saharan Africa [1]. The mortality and the loss of productivity due to the illness, has devastating effects on cognitive development in children surviving the disease, leaving many disabled for life [2]. Since the discovery of the connection between Anopheles vectors and malarial transmission in 1897,

\footnotetext{
*Correspondence: r.djouaka@cgiar.org

${ }^{1}$ International Institute of Tropical Agriculture, Cotonou 08 BP 0932, Benin

Full list of author information is available at the end of the article
}

vector control strategies have been the most widely used malarial control measures [3]. These measures (based on insecticide use) are insecticide treated bed-nets (ITN) and indoor residual spraying (IRS), both of which have been shown to be effective for reducing malaria prevalence in Africa [4]. One of the insecticides of choice for IRS is DDT (dichloro-diphenyl-trichloro-ethane) because of its high insecticidal activity, low acute mammalian toxicity, wide spectrum use, low price, and long duration of activity.

The availability of dichlorodiphenyltrichloroethane (DDT) and other insecticides in the 1940s marked a new 
era for malarial control in the world. The effectiveness of DDT against indoor resting mosquitoes led to the adoption of the Global Eradication Programme of Malaria in 1955, coordinated and supported by the World Health Organization (WHO). Although the use of DDT raises concerns of potential harm to the environment and human health, mainly because of the persistent and bioaccumulative nature of DDT and its potential to magnify through the food chain, it continued to be used for pest control, for which exemptions were granted by the federal government and it is still available for public health use today [5].

Inevitably, the major malaria vectors, Anopheles gambiae and Anopheles funestus, have developed resistance to this insecticide. The basic mechanisms underlying insecticide resistance include insecticide target-site mutations, and increased metabolic detoxification of the insecticide through overproduction or elevated enzymatic activity [6]. Three enzyme families are primarily involved in insecticide detoxification: the carboxylesterases (COEs), glutathione-S-transferases (GSTs) and cytochrome P450s (P450s). DDT resistance in An. gambiae can be due either to a specific detoxification mechanism (glutathione-Stransferase) or to a nerve insensitivity resulting from a modification of the target site (sodium channel). The latter, governed by the $k d r$ gene, reduces both the knockdown and lethal effects of DDT [7]. In West Africa, it induces a cross-resistance to pyrethroids, which also depends on $k d r$ mutation $[7,8]$. In contrary, no $k d r$ mutation has been detected in An. funestus so far [9-11]. Indeed, a single amino acid change in the binding pocket of the glutathione-S-transferase epsilon 2 (GSTe2) gene, coupled with increased transcription of this gene, confers a high level of DDT resistance and also cross-resistance to pyrethroids in An. funestus. Furthermore, analysis of GSTe2 polymorphism established that the L119F-Gste2 mutation is tightly associated with metabolic resistance to DDT and its geographical distribution strongly correlates with DDT resistance patterns across Africa [12]. Nevertheless, the strong contrast in the allele frequencies of the L119F-GSTe2 frequencies despite the similar resistance profile recorded in An. funestus populations from two localities in Ghana [13] suggest that possible barriers to gene flow could exist between populations of the same country. Such differences in the underlying resistance mechanisms should be taken into account when designing suitable insecticide resistance management strategies. In southern Benin (Kpome and Pahou), An. funestus was found to be highly resistant to DDT [14] [15] while the population from Tanongou was moderately resistant to DDT with $90 \%$ mortality [16]. Also, as GSTe2 gene has been associated with DDT resistance patterns across Africa, this study aimed to investigate the role of the GSTe2 gene in DDT resistance across Benin to fill the knowledge gap by checking if this resistance is driven by the same mechanism.

\section{Methods \\ Samples description}

In this study, mosquitoes from the previously published research results were used to further describe the molecular basis of DDT resistance in An. funestus population from different localities [12, 14-16]. Mosquito samples generated from the previous investigation were used for genetic analysis in this work.

\section{Study area and mosquito collection}

Adult anopheles mosquitoes were collected from three (3) locations in Benin: Kpome in South-Est $\left(6^{\circ} 55^{\prime} \mathrm{N}\right.$, $\left.2^{\circ} 19^{\prime} \mathrm{E}\right)$, Pahou $\left(6^{\circ} 23^{\prime} \mathrm{N}, 2^{\circ} 13^{\prime} \mathrm{E}\right)$ in South-West and Tanongou in North West $\left(10^{\circ} 48^{\prime} \mathrm{N}, 1^{\circ} 26^{\prime} \mathrm{E}\right)$. Mosquitoes were also collected in South-West Burkina Faso $\left(11^{\circ}\right.$ $23^{\prime} \mathrm{N}, 4^{\circ} 24^{\prime} \mathrm{E}$ ) (Fig. 1). The selected sites are located in close proximity with rivers, swamps as these permanent water bodies are suitable breeding sites for An. funestus. After obtaining consent from village chiefs and house owners, indoor resting mosquitoes were collected from December 2013 to March 2014 inside households using electric aspirator. Blood fed mosquitoes collected were kept in cups until fully gravid before being subjected to the forced-egg laying technique [17]. The eggs obtained were pooled and reared in a mineral water. Larvae were reared under standard insectary conditions $\left(26 \pm 2{ }^{\circ} \mathrm{C}\right.$ with a relative humidity of $80 \%$ ) and were fed daily with Tetramin $^{\text {TM }}$ baby fish food. The water of each larvae bowl was changed every two days to reduce mortality. F1 adult generated were pooled in cages for subsequent analyses.

\section{Microarrays}

A custom microarray chip containing 44,000 probes $(4 \times 44 \mathrm{k})$ [18] was used to identify the set of genes associated with DDT resistance in Pahou and Burkina-Faso. The $8 \times 60 \mathrm{k}$ (60 mer) Agilent An. funestus chip was used to screen for the genes involved in resistance of An. funestus from Kpome. This Agilent microarray chip was designed using the eArray program (Agilent, Santa Clara, CA, USA) (A-MEXP-2374) by adding the 15,527 expressed sequence tags (ESTs) generated from another transcriptome sequencing of An. funestus [19] to the previous $4 \times 44 \mathrm{k}$ array (A-MEXP-2245) [18]. Labelled cRNA was obtained from three biological replicates (10 mosquitoes per replicate) for the following samples: (i) resistant (R) (mosquitoes alive after a 1-h exposure to $4 \%$ DDT); (ii) control (C) (mosquitoes unexposed to insecticide and thus representative of the wild-type population); and (iii) susceptible (S) (unexposed mosquitoes 


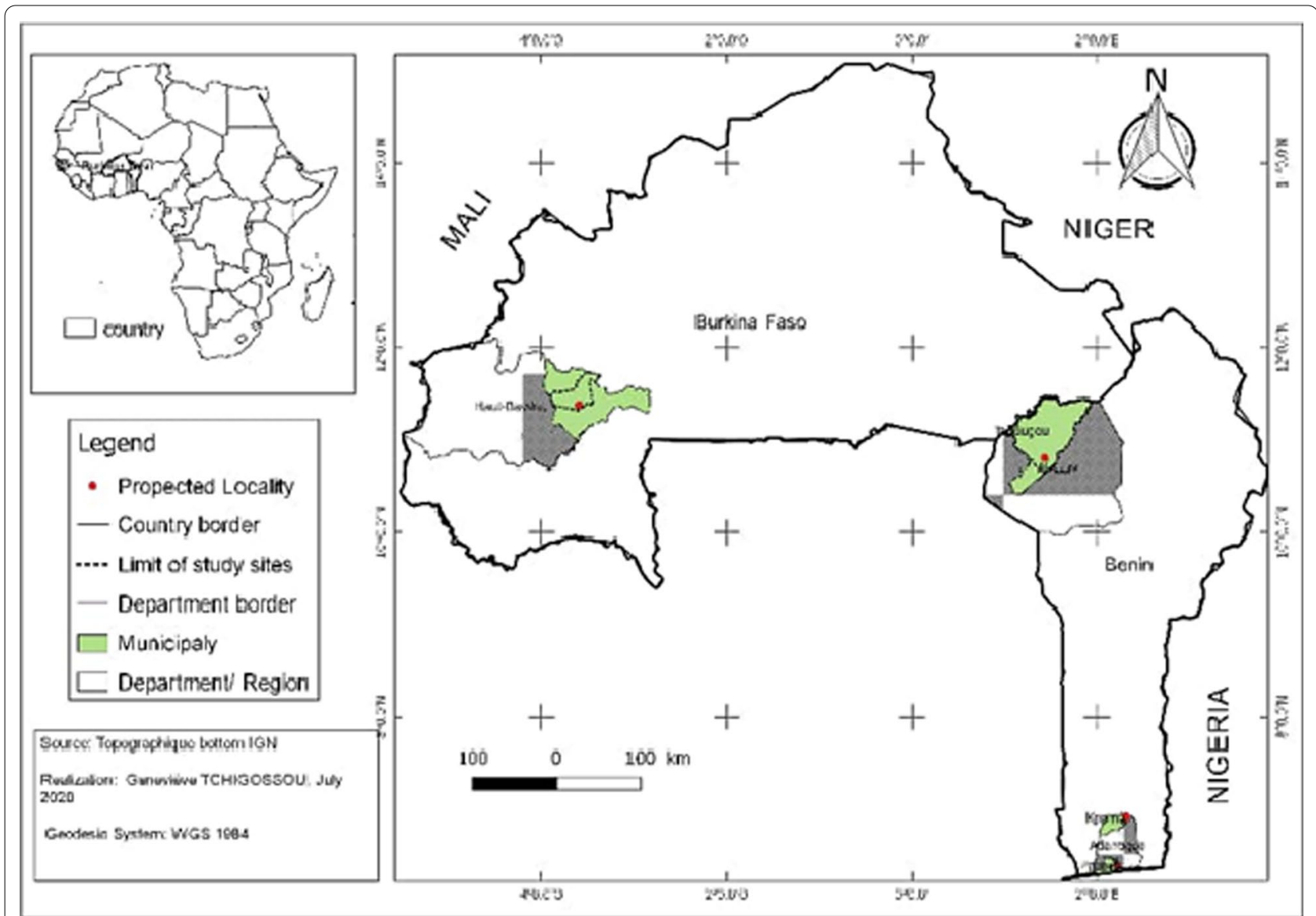

Fig. 1 Map showing the study sites

from the fully susceptible laboratory strain of An. funestus: FANG) making a total of 60 mosquitoes per locality (Pahou, Kpome and Burkina-Faso). Complementary RNA (cRNA) was amplified from each sample using the Agilent Quick Amp Labelling Kit (two-colour) following the manufacturer's protocol. These cRNA were reciprocally hybridized against each other comparing R-S for resistant $v s$. susceptible, C-S for control vs. susceptible. Microarray data were analyzed using Genespring GX 13.0 software. To identify differentially expressed genes, a cut-off of twofold-change (FC) and a statistical significance of $\mathrm{P}<0.05$ using Storey with boostrapping correction for multiple testing were applied. These results were compared to those obtained from Kpome [20].

\section{Quantitative reverse transcriptase PCR}

Three genes (GSTe2, CYP6P9a and CYP6P9b) (Table 1) up-regulated from the microarray analysis and mostly associated with DDT and pyrethroids resistance [12, $14,18,21]$ were assessed by qRT-PCR to validate their expression pattern using the three biological replicates for resistant, control, and FANG. cDNA from the
Resistant (R), Control (C) and FANG (S) populations were synthesized using one microgram of total RNA from each of the three biological replicates. The relative expression level and FC of each target gene in $\mathrm{R}$ and $\mathrm{C}$ relative to $\mathrm{S}$ were calculated according to the $2-\Delta \Delta \mathrm{CT}$ method incorporating the PCR efficiency [22] after normalization with the housekeeping genes ribosomal protein S7 (RSP7; AFUN007153-RA), and actin (Actin; AFUN006819) (Table 1). The results were compared to those obtained in Kpome.

\section{Genotyping of L119F-GSTe2 resistance}

The role of the L119F-Gste2 mutation recently shown to play a major role in the DDT resistance was assessed. Field-collected An. funestus sensu stricto (s.s.) females from each selected location were genotyped using a Taqman assay [12]. The reaction was performed in a 10 - $\mu$ l final volume containing $1 \times$ SensiMix (Bioline, London, UK), $800 \mathrm{nM}$ of each primer and $200 \mathrm{nM}$ of each probe using an Agilent MX3005P machine. The following cycling conditions were used: $10 \mathrm{~min}$ at $95^{\circ} \mathrm{C}, 40$ cycles of $15 \mathrm{~s}$ at $92{ }^{\circ} \mathrm{C}$ and $1 \mathrm{~min}$ at $60^{\circ} \mathrm{C}$. Two probes labelled 
Table 1 List of top upregulated detoxification gene in Anopheles funestus from Pahou and Burkina-Faso exposed and unexposed to DDT

\begin{tabular}{|c|c|c|c|c|c|}
\hline \multirow[t]{2}{*}{ Probe name } & \multirow[t]{2}{*}{ Systematic name } & \multirow{2}{*}{$\begin{array}{l}\text { Burkina-Faso } \\
\text { Rddt-S }\end{array}$} & \multicolumn{2}{|l|}{ Pahou } & \multirow[t]{2}{*}{ Description } \\
\hline & & & Rddt-S & C-S & \\
\hline CUST_1822_PI406199769 & combined_c920 (Gste2) & 3.3 & 35.6 & 11.9 & Glutathione-s-transferase gst \\
\hline CUST_9502_PI406199769 & combined_c4812 & 3.0 & 2.8 & 2.1 & Short-chain dehydrogenase \\
\hline CUST_2953_PI406199769 & combined_c1489 & 2.1 & 3.6 & 3.0 & Argininosuccinate lyase \\
\hline CUST_111_PI406199775 & CYP4D26 & 2.0 & 2.1 & 3.3 & Cytochrome p450 \\
\hline CUST_13272_PI406199769 & combined_c6791 & 6.6 & 2.6 & & Cytochrome p450 \\
\hline CUST_2464_PI406199772 & CD578169.1 & 2.4 & 3.7 & & Trypsin \\
\hline CUST_15002_PI406201128 & AGAP007662-RA__L $2 \mathrm{~L}$ & 2.2 & 4.7 & & Short-chain dehydrogenase \\
\hline CUST_15001_PI406201128 & AGAP007662-RA & 2.2 & 6.1 & & Short-chain dehydrogenase \\
\hline CUST_48_PI406199775 & CYP6z3 & 2.1 & 2.5 & & Cytochrome p450 \\
\hline CUST_3754_PI406199772 & CD577506.1 & 3.4 & & 4.1 & Cuticle protein \\
\hline CUST_639_PI406199788 & gb-GSTS1_2 & 3.4 & & 3.6 & Glutathione s-transferase \\
\hline CUST_7429_PI406199769 & combined_c3760 & 2.8 & & 3.2 & Chymotrypsin 1 \\
\hline CUST_7428_PI406199769 & combined_c3760 & 2.4 & & 3.5 & Chymotrypsin 1 \\
\hline CUST_1963_PI406199772 & CD664227.1 & 2.2 & & 2.5 & Alcohol dehydrogenase \\
\hline CUST_633_PI406199788 & gb-GSTO1 & 2.1 & & 2.1 & Glutathione s-transferase \\
\hline CUST_102_PI406199788 & gb-COE15O & 2.1 & & 3.2 & Carboxylesterase \\
\hline CUST_4649_PI406199798 & AGAP003343-RA__2R & 2.1 & & 2.1 & Cytochrome p450 \\
\hline CUST_4923_PI406199772 & BU038981 & 2.0 & & 2.1 & Alcohol dehydrogenase \\
\hline CUST_483_PI406199788 & gb-CYP6Z4 & 2.0 & & 2.2 & Cytochrome p450 \\
\hline CUST_3109_PI406199772 & CD577844.1 & & 5.0 & 2.0 & Cuticle protein \\
\hline CUST_3835_PI406199772 & CD577459.1 & & 4.7 & 2.4 & Cuticle protein \\
\hline CUST_9503_PI406199769 & combined_c4812 & & 3.2 & 2.5 & Short-chain dehydrogenase \\
\hline CUST_14376_PI406199769 & combined_c7513 & & 2.6 & 3.5 & Glutathione transferase \\
\hline CUST_345_PI406199788 & gb-CYP4D17 & & 2.5 & 3.1 & Cytochrome p450 \\
\hline CUST_2520_PI406199772 & CD578141.1 & & 2.5 & 2.2 & Short-chain dehydrogenase \\
\hline CUST_2550_PI406199769 & combined_c1287 & & 2.3 & 2.8 & Aldehyde dehydrogenase \\
\hline CUST_2551_PI406199769 & combined_c1287 & & 2.3 & 3.5 & Aldehyde dehydrogenase \\
\hline CUST_7029_PI406199769 & combined_c3556 & & 2.2 & 2.3 & Cytochrome p450 \\
\hline CUST_2914_PI406199772 & CD577943.1 & & 2.2 & 2.3 & Short-chain dehydrogenase \\
\hline CUST_1090_PI406199798 & AGAP000881-RA_ $X$ & & 2.1 & 2.3 & Aldehyde dehydrogenase \\
\hline CUST_1964_PI406199772 & CD664227.1 & & 2.0 & 2.6 & Alcohol dehydrogenase \\
\hline CUST_5005_PI406199798 & AGAP003680-RA__ 2R & 3.7 & & & Abc transporter \\
\hline CUST_7696_PI406199798 & AGAP008141-RA__ 3R & 2.5 & & & Argininosuccinate lyase \\
\hline CUST_10700_PI406199798 & AGAP009850-RA__3R & 2.3 & & & Abc transporter \\
\hline CUST_3946_PI406199772 & CD577403.1 & 2.2 & & & Glutathione s-transferase \\
\hline CUST_4649_PI406199798 & AGAP003343-RA__ 2R & 2.1 & & & Cytochrome p450 \\
\hline CUST_8727_PI406199769 & combined_c4419 & 2.1 & & & Abc transporter \\
\hline CUST_12208_PI406199769 & combined_c6213 & 2.0 & & & Argininosuccinate lyase \\
\hline CUST_44_PI406199775 & CYP6z1 & & 3.5 & & Cytochrome p450 \\
\hline CUST_27_PI406199775 & CYP6P9a & & 2.6 & & Cytochrome p450 \\
\hline CUST_11_PI406199775 & CYP6P1 & & 2.1 & & Cytochrome p450 \\
\hline CUST_13469_PI406199769 & combined_c6910 & & 2.1 & & Glutathione s-transferase e2 \\
\hline CUST_3488_PI406199769 & combined_c1762 & & 2.1 & & Abc transporter \\
\hline CUST_402_PI406199788 & gb-CYP6AA2 & & & 3.6 & Cytochrome p450 \\
\hline CUST_353_PI406199788 & gb-CYP4G17 & & & 2.9 & Cytochrome p450 \\
\hline CUST_375_PI406199788 & gb-CYP4H24 & & & 2.9 & Cytochrome p450 \\
\hline CUST_3620_PI406199772 & CD577573.1 & & & 2.8 & Glutathione s-transferase \\
\hline
\end{tabular}


Table 1 (continued)

\begin{tabular}{|c|c|c|c|c|c|}
\hline \multirow[t]{2}{*}{ Probe name } & \multirow[t]{2}{*}{ Systematic name } & \multirow{2}{*}{$\begin{array}{l}\text { Burkina-Faso } \\
\text { Rddt-S }\end{array}$} & \multicolumn{2}{|l|}{ Pahou } & \multirow[t]{2}{*}{ Description } \\
\hline & & & Rddt-S & C-S & \\
\hline CUST_277_PI406199788 & gb-CYP325D1 & & & 2.8 & Cytochrome p450 \\
\hline CUST_374_PI406199788 & gb-CYP4H24 & & & 2.8 & Cytochrome p450 \\
\hline CUST_386_PI406199788 & gb-CYP4J10 & & & 2.6 & Cytochrome p450 \\
\hline CUST_401_PI406199788 & gb-CYP6AA2 & & & 2.5 & Cytochrome p450 \\
\hline CUST_237_PI406199788 & gb-CYP305A3 & & & 2.5 & Cytochrome p450 \\
\hline CUST_372_PI406199788 & gb-CYP4H19 & & & 2.3 & Cytochrome p450 \\
\hline CUST_431_PI406199788 & gb-CYP6M3 & & & 2.2 & Cytochrome p450 \\
\hline CUST_5107_PI406201128 & AGAP002204-RA_CYP325D1 & & & 2.1 & Cytochrome p450 \\
\hline CUST_407_PI406199788 & gb-CYP6AF1/2 & & & 2.0 & Cytochrome p450 \\
\hline CUST_3938_PI406199772 & CD577407.1 & & & 2.0 & Glutathione s-transferase \\
\hline
\end{tabular}

with fluorochromes FAM and HEX were used. The FAM detected the mutant allele while the HEX detected the wild allele.

\section{Genetic diversity of GSTe2 across Benin}

A full-length GSTe2 (exons and introns) was amplified from 10 field-collected female mosquitoes from each location using Phusion High-Fidelity DNA Polymerase (Fermentas, Burlington, Ontario, Canada) and the following conditions: 1 cycle at $95{ }^{\circ} \mathrm{C}$ for $5 \mathrm{~min} ; 35$ cycles of $94{ }^{\circ} \mathrm{C}$ for $20 \mathrm{~s}, 57{ }^{\circ} \mathrm{C}$ for $30 \mathrm{~s}$ and $72{ }^{\circ} \mathrm{C}$ for $60 \mathrm{~s}$; and 1 cycle at $72{ }^{\circ} \mathrm{C}$ for $5 \mathrm{~min}$. The PCR products were purified using the QIAquick PCR Purification Kit (Qiagen, Valencia, CA, USA) and subsequently sequenced. The GSTe2L119F polymorphic position was detected through a manual analysis of sequence traces and sequences alignments were done using BioEdit. Data were exported to the software DnaSp-version 5.10.01 to detect genetic variability of the GSTe2 gene among the different populations. A maximum likelihood phylogenetic tree for the coding sequences of GSTe2 in the five localities was constructed using MEGA 5.2 [23]. The best model was firsly assessed and this indicated that the Jukes-Cantor model best describes the GSTe 2 haplotypes. This was then used to generate the maximum likehood tree using MEGA 5.2. In addition, the level of pairwise genetic differentiation between the populations were determined in dnasp 5.10 using the Kst statistic [24] and the neighbour-joining tree was built using Mega 6.06 [24].

\section{Results}

\section{Susceptibility profiles to insecticides}

The Pahou population (Benin) had previously been described as highly DDT resistant [14] with no mortality $24 \mathrm{~h}$ after $1 \mathrm{~h}$ of exposure. The WHO bioassays conducted in Kpome [15] indicated that this An. funestus population, which is located approximately $100 \mathrm{~km}$ from Pahou, was also resistant to DDT, with $9.1 \pm 2.5 \%$ mortality $24 \mathrm{~h}$ after $1 \mathrm{~h}$ of exposure to 4\% DDT for females. The population from Tanongou was moderately resistant to DDT with $90 \%$ mortality [16].

\section{Genome-wide transcription microarray analysis}

A genome-wide transcription analysis enabled us to identify the set of genes associated with DDT resistance in Pahou (Benin) and Burkina-Faso (Table 2; Fig. 2). These results were compared to Kpome (Benin) (Table 3; Fig. 3) results where high level of DDT resistance were recorded recently [15]. A total of 6610 probes were differentially expressed $(\mathrm{FC} \geq 2$ at $\mathrm{P}<0.05)$ between the DDT-resistant samples from Pahou and the susceptible strain FANG with 4637 up regulated and 1973 down regulated. The comparison between the control wild type samples (Control) from Pahou and the susceptible strain FANG showed 9756 probes differentially expressed with 7489 up regulated and 2267 down regulated. In BurkinaFaso, a total of 3602 probes were differentially expressed between the DDT-resistant samples and the susceptible FANG. When comparison was made between samples from Pahou and Burkina-Faso, 1007 probes were differentially expressed with 779 over expressed and 228 down expressed as presented in (Table 2, Fig. 2). On the other hand, samples from Pahou were also compared to those from Kpome (20) and 852 common probes were differentially expressed with 326 up regulated and 526 down regulated (Table 3; Fig. 2). The most common upregulated detoxification gene in Benin and Burkina-Faso was a glutathione S-transferase, GSTe2 with a fold change FC of 35.6; 13.3 and 3.3 in DDT resistant samples compared to susceptible FANG respectively in Pahou, Kpome and Burkina-Faso. Due to the limited number of emerging mosquitoes, we could not perform the microarrays 
Table 2 List of top upregulated detoxification gene in Anopheles funestus from Pahou and Kpome exposed and unexposed to DDT

\begin{tabular}{|c|c|c|c|c|c|}
\hline & & Pahou & Kpome & & \\
\hline Probe name & Systematic name & R-S & Rddt-S & Ortholog in An. gambiae & Description \\
\hline CUST_9227_PI426302897 & Afun009227 & 29.2 & 22.2 & AGAP008141-PA & Argininosuccinate lyase \\
\hline CUST_13921_PI426302897 & Afun013921 & 27.4 & 17.3 & AGAP006709-PA & Chymotrypsin 1 \\
\hline CUST_500_PI426302897 & Afun000500 & 17.1 & 36.2 & NA & Glycogenin \\
\hline CUST_11037_PI426302897 & Afun011037 & 13.1 & 6.5 & AGAP003581-PA & Alcohol dehydrogenase \\
\hline CUST_45_PI426302897 & Afun000045 (GSTE2) & 12.2 & 13.3 & AGAP009194-PA & Glutathione-s-transferase gst \\
\hline CUST_1459_PI406199769 & combined_c738 & 10.9 & 14.9 & & Short-chain dehydrogenase \\
\hline CUST_4223_PI426302897 & Afun004223 & 9.5 & 12.8 & AGAP008358-PA & Cytochrome p450 4d1 \\
\hline CUST_1822_PI406199769 & combined_c920 & 9.4 & 11.5 & & Glutathione-s-transferase gst \\
\hline CUST_7769_PI426302897 & Afun007769 (CYP9K1) & 6.1 & 3.0 & AGAP000818-PA & Cytochrome p450 cyp9k1 \\
\hline CUST_1392_PI426302897 & Afun001392 & 6.0 & 2.5 & NA & Glycine dehydrogenase \\
\hline CUST_6930_PI426302897 & Afun006930 (CYP6M7) & 4.9 & 4.0 & AGAP008212-PA & Cytochrome p450 6a8 \\
\hline CUST_8445_PI426302897 & Afun008445 (GSTE4) & 4.4 & 4.3 & AGAP009193-PA & Glutathione-s-transferase gst \\
\hline CUST_12343_PI426302897 & Afun012343 (CYP4H18) & 4.1 & 5.2 & AGAP008358-PA & Cytochrome p450 4d1 \\
\hline CUST_3220_PI426302897 & Afun003220 & 4.0 & 10.8 & AGAP002867-PA & Cytochrome p450 \\
\hline CUST_7646_PI426302897 & Afun007646 & 3.9 & 2.9 & AGAP006225-PA & Aldehyde oxidase \\
\hline CUST_5559_PI426302897 & Afun005559 & 3.8 & 3.5 & AGAP008783-PA & Arginase \\
\hline CUST_7469_PI426302897 & Afun007469 (CYP9J3) & 2.6 & 2.0 & AGAP012296-PA & Cytochrome p450 \\
\hline CUST_8615_PI426302897 & Afun008615 (CYP6AA1) & 2.6 & 5.1 & AGAP002862-PA & Cytochrome p450 \\
\hline CUST_13218_PI426302897 & Afun013218 (CYP315A1) & 2.3 & 2.3 & AGAP000284-PA & Cytochrome p450 \\
\hline CUST_15331_PI426302897 & Afun015331 (CYP307A1) & 29.4 & 3.4 & AGAP001039-PB & Cytochrome p450 307a1 \\
\hline CUST_9088_PI426302897 & Afun009088 & 4.7 & 9.1 & AGAP004900-PA & Serine protease \\
\hline CUST_14264_PI426302897 & Afun014264 & 3.8 & 2.7 & AGAP003785-PE & Glucose dehydrogenase \\
\hline CUST_25_PI406199775 & CYP6P9a & 3.4 & 2.8 & & Cytochrome p450 \\
\hline CUST_10_PI426302915 & CYP6M4.seq & 3.2 & 2.3 & & Cytochrome p450 \\
\hline CUST_13481_PI426302897 & Afun013481 (GSTE1) & 2.2 & 2.5 & AGAP009195-PA & Glutathione-s-transferase gst \\
\hline CUST_1_PI426302915 & CYP6M1a.seq & 2.8 & & & Cytochrome p450 \\
\hline CUST_9335_PI426302897 & Afun009335 (CYP6AG1) & 2.7 & & AGAP003343-PA & Cytochrome p450 \\
\hline CUST_22_PI426302915 & CYP6S2.seq & 7.1 & & & Cytochrome p450 \\
\hline CUST_1097_PI406199769 & combined_c557 & 5.1 & & & Trypsin \\
\hline CUST_7369_PI426302897 & Afun007369 (CYP6P9b) & 4.4 & & AGAP002865-PA & Cytochrome p450 \\
\hline CUST_3246_PI426302897 & Afun003246 & 4.1 & & AGAP006220-PA & Aldehyde oxidase \\
\hline CUST_12197_PI426302897 & Afun012197 (CYP304B1) & 4.0 & & AGAP003066-PA & Cytochrome p450 \\
\hline CUST_2464_PI406199772 & CD578169.1 & 3.9 & & & Trypsin \\
\hline CUST_1096_PI406199769 & combined_c557 & 3.8 & & & Trypsin \\
\hline CUST_12666_PI426302897 & Afun012666 (CYP314A1) & 3.7 & & AGAP002429-PA & Cytochrome p450 \\
\hline CUST_5005_PI406199798 & AGAP003680-RA__ 2R & 3.4 & & AGAP003680-RA__R $2 R$ & Abc transporter \\
\hline CUST_9522_PI426302897 & Afun009522 (CYP9J3) & 2.8 & & AGAP012292-PA & Cytochrome p450 \\
\hline CUST_7722_PI426302897 & Afun007722 & 2.7 & & AGAP009850-PA & Abc transporter \\
\hline CUST_27_PI426302915 & CYP6Z1_rvcpl_fixed.seq & 2.3 & & & Cytochrome p450 \\
\hline CUST_10_PI406199775 & CYP6P1 & 2.2 & & & Cytochrome p450 \\
\hline CUST_9068_PI426302897 & Afun009068 & 2.2 & & AGAP006948-PB & Cytochrome b561 \\
\hline CUST_14535_PI426302897 & Afun014535 (CYP301A1) & 2.1 & & AGAP006082-PA & Cytochrome p450 \\
\hline CUST_13288_PI426302897 & Afun013288 & 2.0 & & AGAP002278-PA & Abc transporter \\
\hline CUST_12342_PI426302897 & Afun012342 (CYP4H14) & 2.0 & & AGAP008358-PA & Cytochrome p450 4d1 \\
\hline CUST_13475_PI426302897 & Afun013475 & & 3.2 & AGAP003582-PA & Alcohol dehydrogenase \\
\hline CUST_5448_PI426302897 & Afun005448 (CYP302A1) & & 2.6 & AGAP005992-PA & Cytochrome p450 \\
\hline CUST_8823_PI426302897 & Afun008823 (CYP4D15) & & 2.4 & AGAP002418-PA & Cytochrome p450 \\
\hline
\end{tabular}


Table 2 (continued)

\begin{tabular}{lllll}
\hline \multicolumn{3}{c}{ Pahou } & Kpome & \\
\hline CUST_7301_PI426302897 & Afun007301 (CYP4J5) & 2.2 & AGAP006048-PA & Cytochrome p450 \\
CUST_208_PI406199788 & gb-CYP12F3 & 2.1 & & Cytochrome p450 \\
CUST_10630_PI426302897 & Afun010630 & 2.1 & AGAP002866-PA & Cytochrome p450 \\
CUST_11942_PI426302897 & Afun011942 & & AGAP011509-PA & Carboxylesterase \\
CUST_3489_PI406199769 & combined_C1762 & & & Abc transporter \\
CUST_8026_PI426302897 & Afun008026 & AGAP003578-PA & Aldehyde dehydrogenase \\
\hline
\end{tabular}

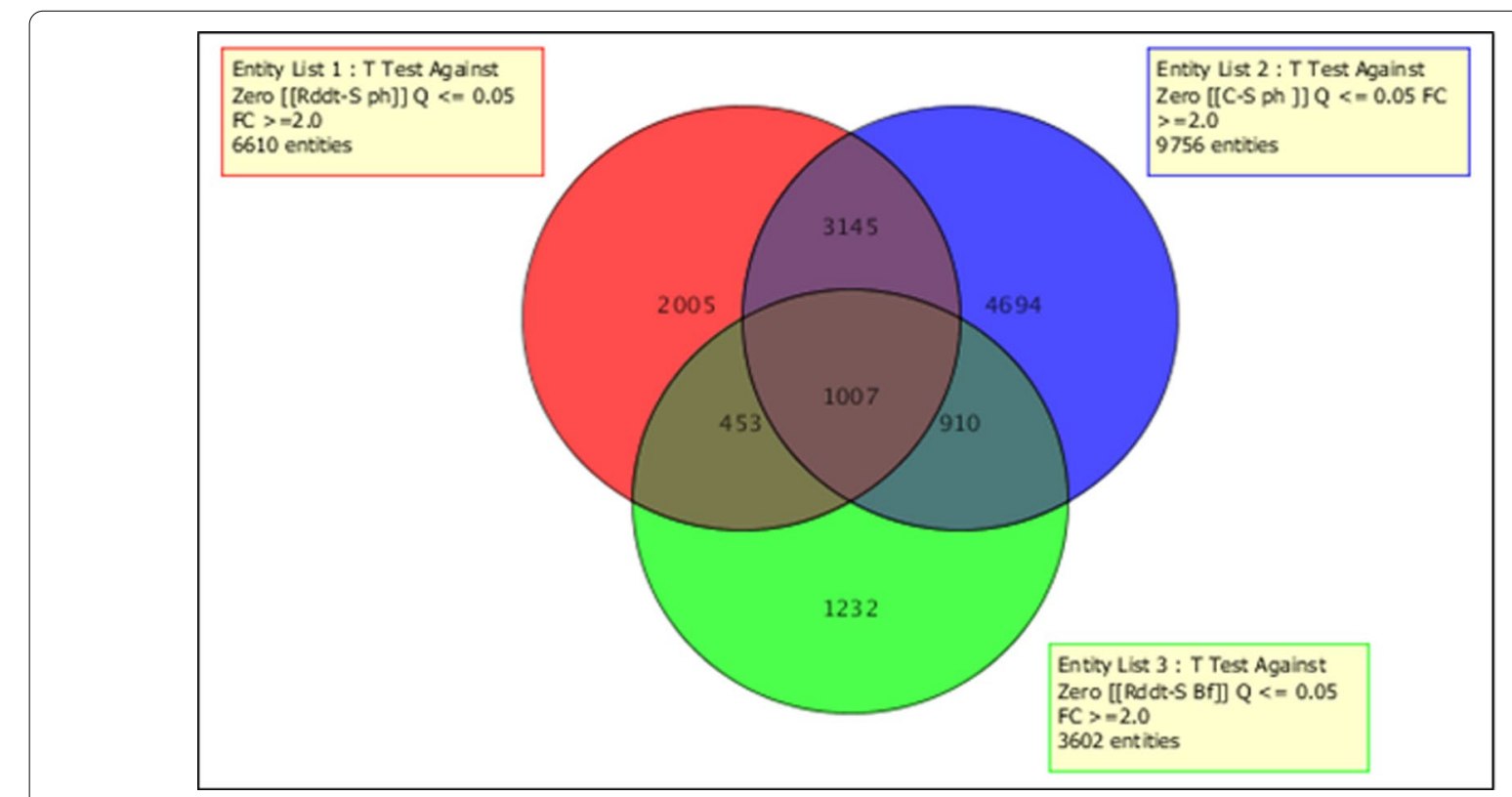

Fig. 2 Summary of probes differentially expressed in Pahou and Burkina-Faso samples. The Venn diagrams show the number of probes significantly $(P \leq 0.05)$ up or down-regulated ( $F C \geq 2$ ) in each comparison as well as the commonly expressed probes

Table 3 Summary statistics for polymorphism GSTe2 gene in F0 An. funestus from five localities

\begin{tabular}{lllllllll}
\hline & N (2n) & S & $\mathbf{n}$ & $\mathbf{k}$ & h & hd & D & D* \\
\hline Kpome (Benin) & 18 & 0 & 0 & - & 1 & 0 & - & - \\
Pahou (Benin) & 48 & 5 & 0.00192 & 1.41844 & 2 & 0.284 & $0.63 \mathrm{~ns}$ & $1.10 \mathrm{~ns}$ \\
Doukonta (Benin) & 18 & 6 & 0.00103 & 0.76471 & 3 & 0.307 & $-1.84 \mathrm{~s}$ & $-2.14 \mathrm{~ns}$ \\
Akaka Remo (Nigeria) & 12 & 8 & 0.00246 & 1.81818 & 5 & 0.576 & $-1.25 \mathrm{~ns}$ & $-1.48 \mathrm{~ns}$ \\
Tanongou (Benin) & 4 & 4 & 0.00361 & 2.66667 & 2 & 0.667 & $2.08 \mathrm{~ns}$ & $2.08 \mathrm{~s}$ \\
Burkina-Faso & 4 & 2 & 0.00180 & 1.33333 & 2 & 0.667 & $1.89 \mathrm{~ns}$ & $1.89 \mathrm{~ns}$ \\
\hline
\end{tabular}

analysis in Tanongou (Benin). Several gene families among which the most preeminent were the cytochrome P450 genes were also over expressed. Beside cytochrome P450s, other genes belonging to multiple gene families included alcohol and aldehyde dehydrogenases were up-regulated.

\section{Validation of the microarray upregulation with qRT-PCR}

Transcription analysis of the candidate resistance genes GSTe2, CYP6P9a and CYP6P9b revealed that these genes are significantly upregulated in An. funestus from Pahou and Kpome. Indeed the GSTe 2 was the most upregulated gene with a fold-change FC of 44.8 [12] in Pahou 


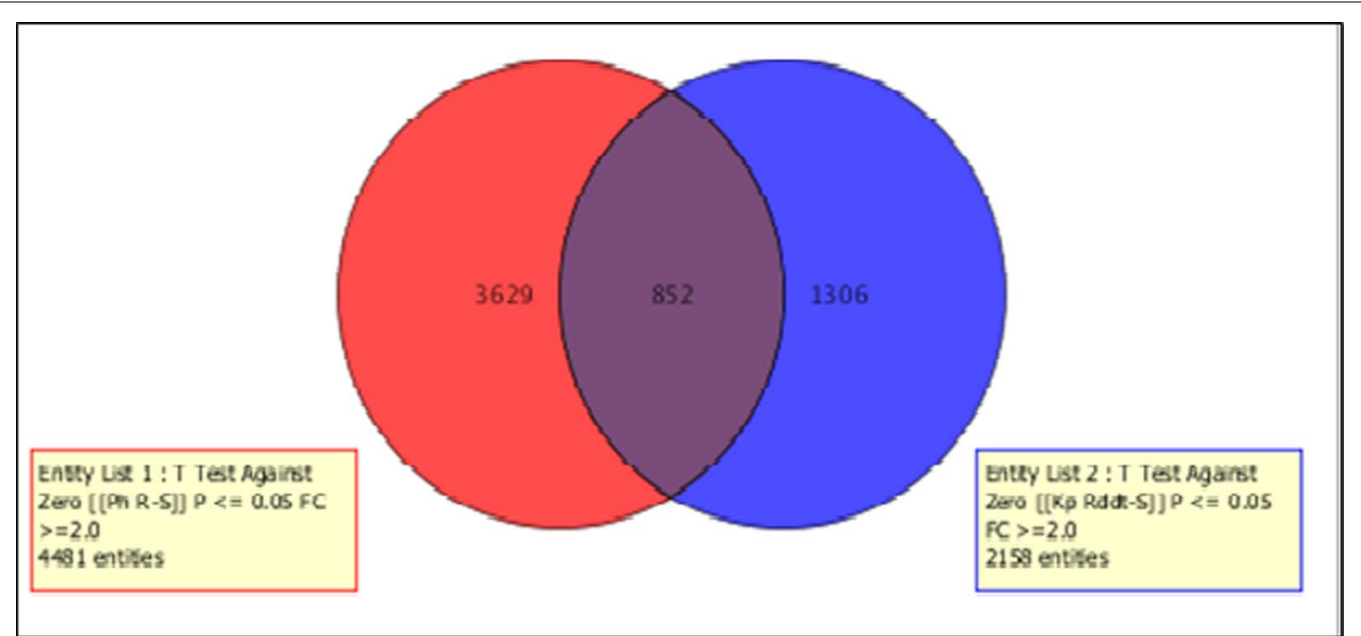

Fig. 3 Summary of probes differentially expressed in Kpome and Pahou samples. The Venn diagrams show the number of probes significantly (P $\leq$ 0.05 ) up or down-regulated ( $F C \geq 2$ ) in each comparison as well as the commonly expressed probes

and 16.2 in Kpome [20] and this expression pattern goes with DDT resistance observed in both localities. The two P450 duplicated genes CYP6P9 $a$ and $C Y P 6 P 9 b$ were also upregulated with a FC of $2.9 ; 7.1$ and $3.7 ; 3.4$, respectively in Pahou and Kpome [12, 20].

\section{Correlation between the L119F mutation and DDT resistance}

The genotyping of the GSTe2-L119F mutation in Kpome, and Doukonta in the southern Benin where high resistance was observed against DDT revealed a high frequency of $96 \%$ and $93 \%$ of the $119 \mathrm{~F}$ in these locations compared to Tanongou in the North Benin (35\%) where moderate resistance was observed to DDT as reported by Djouaka et al. [16]. Also, similar results were reported in Burkina Faso with 25\% of the 119F mutation in correlation with the prevalence of DDT resistance [12].

\section{Role of the GSTe2-L119F mutation in DDT resistance and genetic diversity of Gste 2 gene}

Full length GSTe2 (exons and introns) was successfully amplified and directly sequenced in ten samples from each locality. These localities are Kpome, Pahou, Doukonta in the southern Benin, Tanongou in the northern Benin, Akaka-Remo in the southern Nigeria and BurkinaFaso. The L119F-GSTe2 mutation is the replacement of leucine (CTT) with phenylalanine (TTT) at the position 119. The $\mathrm{C} / \mathrm{C}$ is the homozygote susceptible wild type, the $\mathrm{T} / \mathrm{T}$ is the homozygote mutant genotype while the $\mathrm{C} / \mathrm{T}$ is a codominant genotype. Interestingly, no $\mathrm{T} / \mathrm{T}$ genotype (the homozygous resistant allele) was detected in Tanongou (North Benin) and Burkina Faso population where moderate resistance was recorded against DDT while in others populations highly resistant to DDT were almost all homozygote T/T (Fig. 4). The alignment of 739 bp of the sequenced samples showed a heterogeneity between the An. funestus population analysed as reported in Table 4 . The analysis of maximum likehood phylogenetic tree of GSTe2 indicated that An. funestus populations are structured according to their pattern of DDT resistance. The ML tree shows that sequences from southern Benin cluster closer to those from southern Nigeria where high resistance level was recorded and sequences from Tanongou cluster with those from Burkina-Faso where moderate resistance level was observed (Fig. 5a). This pattern is also supported by the neighbour-joining tree with genetic distances based on Fst estimates (proportion of the total genetic variance contained in a subpopulation) (Fig. 5b). This result suggest the presence of barriers to gene flow that are affecting the spread of resistance genes. In addition, the presence of a large indel in the GSTe 2 gene was

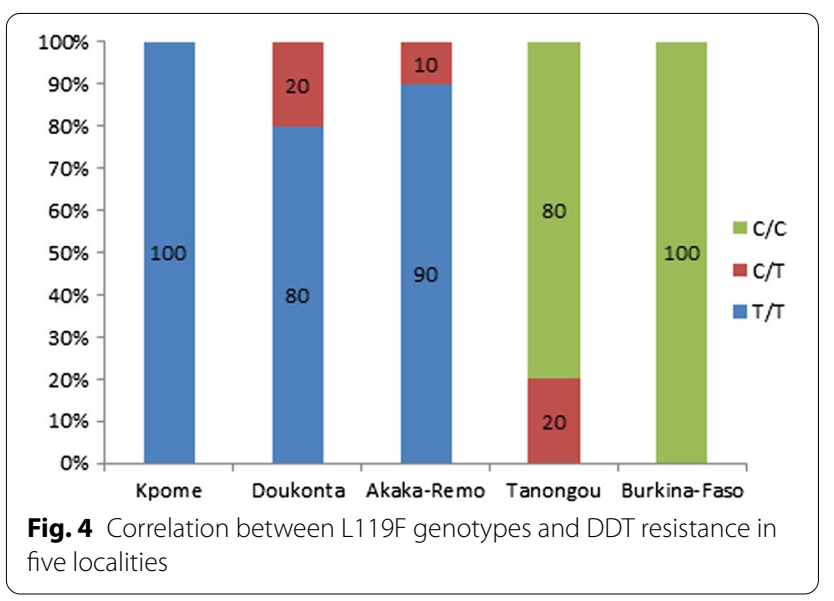


Table 4 Summary statistics for polymorphism GSTe2 gene in F0 An. funestus from five localities

\begin{tabular}{lllllllll}
\hline & N $(\mathbf{2 n})$ & $\mathbf{s}$ & $\mathbf{\pi}$ & $\mathbf{k}$ & $\mathbf{h}$ & hd & D & D* \\
\hline Kpome (Benin) & 18 & 0 & 0 & - & 1 & 0 & - & - \\
Pahou (Benin) & 48 & 5 & 0.00192 & 1.41844 & 2 & 0.284 & $0.63 \mathrm{~ns}$ & $1.10 \mathrm{~ns}$ \\
Doukonta (Benin) & 18 & 6 & 0.00103 & 0.76471 & 3 & 0.307 & $-1.84 \mathrm{~s}$ & $-2.14 \mathrm{~ns}$ \\
Akaka Remo (Nigeria) & 12 & 8 & 0.00246 & 1.81818 & 5 & 0.576 & $-125 \mathrm{~ns}$ & $-1.48 \mathrm{~ns}$ \\
Tanongou (Bruin) & 4 & 4 & 0.00361 & 2.66667 & 2 & 0.667 & $2.08 \mathrm{~ns}$ & $2.08 \mathrm{~s}$ \\
Burkina-Faso & 4 & 2 & 0.00180 & 1.33333 & 2 & 0.667 & $1.89 \mathrm{~ns}$ & $1.89 \mathrm{~ns}$ \\
\hline
\end{tabular}

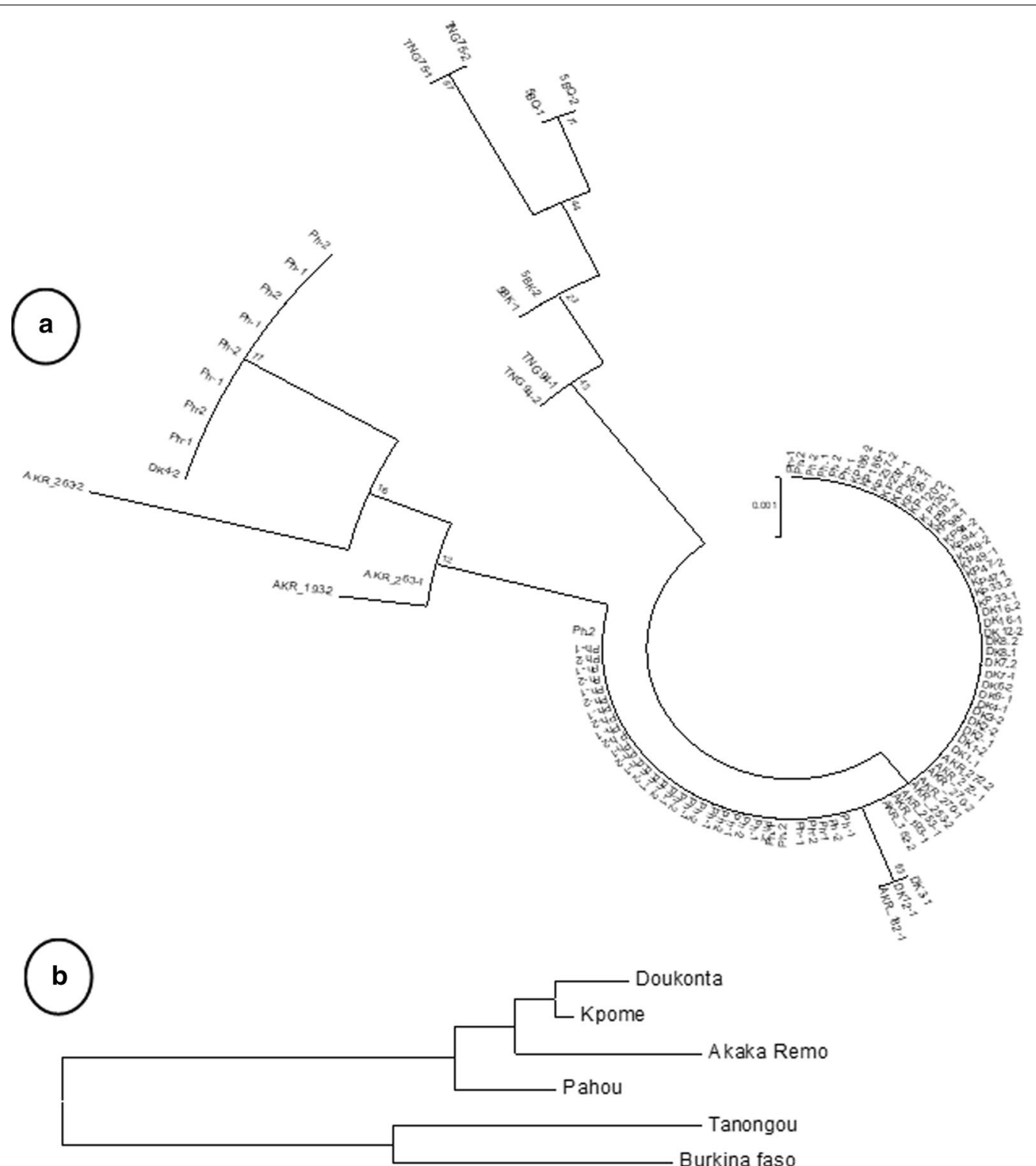

Fig. 5 GSTe2 polymorphism in Anopheles funestus from 6 localities. (a) Maximum likelihood tree of GSTe2 in the 6 localities, (b) Neighbour joining tree of the GSTe2 in the 6 localities 
noticed in the samples from Tanongou and Burkina Faso, but was not present in southern mosquito populations. This requires further investigation.

\section{Discussion}

Insecticide resistance is a complex trait and factors involved vary depending on species, insecticide and population. This research was designed to assess the underlying molecular basis driving DDT resistance in the South-North transect of Benin to improve performances of malaria controls tools.

Physiological resistance to insecticides often involves either mutations in the insecticide target site (target-site resistance), or elevated activity of detoxifying enzymes that metabolise and/or sequester insecticides (metabolic resistance). In the absence of knockdown resistance mutations in the voltage-gate sodium channel in An. funestus [10, 11, 14], this study showed how DDT resistance in this mosquito species is a result of both target-site resistance and up-regulation of a DDT detoxifying enzyme. Overall, this study has revealed GSTe2 gene as a key gene implicated in DDT as a result of elevated expression rather than allelic variation through the GSTe2-L119F mutation. This is in line with previous studies $[2-7,11,12]$ showing that over transcription of the GSTe2 gene confers DDT resistance and cross-resistance to permethrin. It has also been shown that the overexpression of GSTe2 gene in DDT resistant strain of An. gambiae [8, 25] and the overproduction of this gene is very efficient at metabolizing DDT [26]. Also, the GSTe 2 gene has been implicated in DDT resistance in Aedes aegypti species from Thailand [27] showing the important role of the up-regulation of this gene in DDT resistance. Such observations are in accordance with the resistance profile of Pahou and Kpome An. funestus populations, which are highly resistant to DDT compared to Tanongou closer to Burkina-Faso where moderate resistance was recorded. Beside the overexpression of the GSTe2 gene, it is acknowledged that the presence of L119F-GSTe2 mutation confers DDT resistance in $A n$. funestus s.s. populations in West/Central and East Africa [12] and this is in line with the high allelic frequency of this mutation recorded in Kpome and Doukonta. High allelic frequency of the GSTe2-L119F mutation and upregulation of the GSTe2 gene were observed in Kpome, Pahou and Doukonta while low regulation and low allelic frequency of the mutation were observed in Tanongou and Burkina-Faso in correlation with DDT profile observed. The consistent difference observed for this gene between the population of southern Benin (Kpome, Pahou and Doukonta) and that of Tanongou (North Benin) and Burkina-Faso suggest that possible barriers to gene flow exist between these populations. These barriers to gene flow could be due to geographic distance, because gene flow can be restricted by physical barriers separating the populations. Clarke [28] and Duke et al. [29]. also reported that habitat discontinuities may present barriers to gene flow. Furthermore, the genetic and behavioural divergence may be related to differences in the scale of vector control interventions between the regions or an effect of climate change could also explain this phenomenon. Such anti-vector interventions have been found to impact population size of vector populations [30]. Insecticide resistance in vector populations has been widespread with large scale exposure resulting in altered abundance, behavioural shifts and general ecology of major vector populations (e.g. An. funestus, An. gambiae) [31]. However, this observation needs to be confirmed in future studies.

Analysis of the full-length GSTe2 gene shows a possible association between the GSTe2 polymorphism and observed DDT resistance in the 6 localities. The 119F resistant allele is fixed in highly DDT-resistant Benin mosquitoes especially in Pahou, Kpome and Doukonta and in Nigeria (Akaka Remo), but very low in moderate resistant mosquitoes in Tanongou and Burkina-Faso showing the key role of this mutation in DDT resistance as reported by [12]. This study revealed that southern Benin and Nigeria populations of An. funestus are more genetically differentiated as they form a unique cluster compared to North populations. This pattern of genetic diversity of the GSTe2 gene observed in this study support the contrast in resistance patterns between populations of An.funestus. In addition, a significant shift in the over-expression profile of this gene was detected across a South/North transect of Benin in line with the DDT resistance profile observed, showing that the L119FGSTe2 mutation coupled with up-regulation of this gene confer a high level DDT resistance in An. funestus [12]. The consistent differences between the An. funestus population across Benin is likely to impact the design and implementation of resistance management strategies in Benin.

\section{Conclusion}

Effective management of resistance requires an understanding of the dynamics and mechanisms driving resistance. This study shows that molecular basis of DDT resistance in southern Benin An. funestus is associated with L119F-GSTe2 mutation and over-expression of this gene. The variations observed between southern and northern populations of An. funestus could suggest the presence of barriers to gene flow that are affecting the spread of resistance and associated genes. 


\section{Abbreviations}

DDT: Dichlorodiphenyltrichloroethane; qRT-PCR: Quantitative reverse transcriptase polymerase chain reaction; ML: Maximum Likehood phylogenetic tree.

\section{Acknowledgements}

We appreciate Kpome community for their cooperation during field work. We thank Gareth Weedall, Claude Gande and Murielle Soglo for their technical assistance and relevant advice.

\section{Authors' contributions}

RD and CSW designed the study. GT, RA and SMA carried out mosquito collection and GT, RA, SMA and JR reared mosquitoes and performed WHO bioassays. GT and HI performed microarray, qRT-PCR analyses and sequencing of resistance genes. GT, JMR and CSW analysed data. AY gave advise on the study design and contributed to the implementation of the study. GT, RD, JR and CSW wrote the manuscript. All authors read and approved the final manuscript.

\section{Funding}

This work was mainly supported by the Wellcome Trust grants (Ref. 099864/Z/12/Z and 214201/Z/18/Z) awarded to RD and a Wellcome Trust Senior Research Fellowship in Biomedical Sciences to CSW (101893/Z/13/Z). It also received support from the World Health Organization-Tropical Diseases Research (WHO-TDR) grant [B20388] of Nafomon Sogoba (PI), Faculté de Médecine et d'Odontostomatologie (FMOS), Bamako, Mali and the Fp5-A4NH programme of the CGIAR Coordinated by Bernard Bett, Jo Lines, Jeff Waage.

\section{Availability of data and materials}

All data generated or analysed during this study are included in the manuscript and its additional file.

\section{Ethics approval and consent to participate}

Verbal consent was obtained from household heads before mosquito collections.

\section{Consent for publication}

\author{
Not applicable.
}

\section{Competing interests}

The authors declare that they have no competing interests.

\section{Author details}

${ }^{1}$ International Institute of Tropical Agriculture, Cotonou 08 BP 0932, Benin.

${ }^{2}$ University of Abomey Calavi, BP 526, Cotonou, Benin. ${ }^{3}$ Cell Biology and Genetics Unit, Department of Zoology, University of Ibadan, Oyo, Oya State, Nigeria. ${ }^{4}$ Technologies, Engineering and Mathematics, National University of Sciences, Ecole Normale Supérieure de Natitingou, Natitingou, BP 123, Benin. ${ }^{5}$ Liverpool School of Tropical Medicine, Pembroke PlaceLiverpool L3 5QA, UK. ${ }^{6}$ Center for Research in Infectious Diseases (CRID), Yaoundé, Centre Region, Cameroon.

Received: 13 March 2020 Accepted: 17 November 2020 Published online: 17 December 2020

\section{References}

1. WHO. World Malaria Report 2016. Geneva, World Health Organization, 2016.

2. Markley JD, Edmond MB. Post-malaria neurological syndrome: a case report and review of the literature. J Travel Med. 2009;16:424-30.

3. Mabaso ML, Sharp B, Lengeler C. Historical review of malarial control in southern African with emphasis on the use of indoor residual housespraying. Trop Med Int Health. 2004;9:846-56.

4. WHO. Global plan for insecticide resistance management in malaria vectors. Geneva, World Health Organization, 2012.

5. Berry-Cabán CS. DDT and silent spring: fifty years after. J Milit Veterans Health. 2011;19:4.

6. Ranson $\mathrm{H}$, Jensen B, Vulule JM, Wang X, Hemingway J, Collins FH. Identification of a point mutation in the voltage-gated sodium channel gene of Kenyan Anopheles gambiae associated with resistance to DDT and pyrethroids. Insect Mol Biol. 2000;9:491-7.

7. Martinez-Torres D, Chandre F, Williamson MS, Darriet F, Bergé JB, Devonshire AL, et al. Molecular characterization of pyrethroid knockdown resistance $(\mathrm{kdr})$ in the major malaria vector Anopheles gambiae s.s. Insect Mol Biol. 1998;7:179-84.

8. Ranson H, Rossiter L, Ortelli F, Jensen B, Wang X, Roth CW, et al. Identification of a novel class of insect glutathione Stransferases involved in resistance to DDT in the malaria vector Anopheles gambiae. Biochem J. 2001;359:295.

9. Cuamba N, Morgan JC, Irving H, Steven A, Wondji CS. High level of pyrethroid resistance in an Anopheles funestus population of the chokwe district in mozambique. PLoS ONE. 2010;5:e11010.

10. Mulamba C, Riveron JM, Ibrahim SS, Irving H, Barnes KG, Mukwaya LG, et al. Widespread pyrethroid and DDT resistance in the major malaria vector Anopheles funestus in East Africa is driven by metabolic resistance mechanisms. PLOS ONE. 2014;9:e110058.

11. Samb B, Konate L, Irving H, Riveron JM, Dia I, Faye O, et al. Investigating molecular basis of lambda- cyhalothrin resistance in an Anopheles funestus population from Senegal. Parasit Vectors. 2016;9:449.

12. Riveron JM, Yunta C, Ibrahim SS, Djouaka R, Irving H, Menze BD, et al. A single mutation in the GSTe2 gene allows tracking of metabolically based insecticide resistance in a major malaria vector. Genome Biol. 2014;15:R27.

13. Riveron JM, Osae M, Egyir-yawson A, Irving H, Ibrahim SS, Wondji CS. Multiple insecticide resistance in the major malaria vector Anopheles funestus in southern Ghana: implications for malaria control. Parasit Vectors. 2016;9:504.

14. Djouaka R, Irving H, Tukur Z, Wondji CS. Exploring mechanisms of multiple insecticide resistance in a population of the malaria vector Anopheles funestus in Benin. PLoS ONE. 2011;6:e27760.

15. Djouaka R, Riveron JM, Yessoufou A, Tchigossou G, Akoton R, Irving H, et al. Multiple insecticide resistance in an infected population of the malaria vector Anopheles funestus in Benin. Parasit Vectors. 2016;9:453.

16. Djouaka R, Akoton RI, Tchigossou GM, Atoyebi SM, Irving H, Kusimo MO, et al. Mapping the distribution of Anopheles funestus across Benin highlights a sharp contrast of susceptibility to insecticides and infection rate to Plasmodium between southern and northern populations. Wellcome Open Res. 2017;1:28.

17. Morgan JC, Irving H, Okedi LM, Steven A, Wondji CS. Pyrethroid resistance in an Anopheles funestus population from Uganda. PLoS ONE. 2010;5:e27760.

18. Riveron JM, Irving H, Ndula M, Barnes KG, Ibrahim SS, Paine MJl, et al. Directionally selected cytochrome P450 alleles are driving the spread of pyrethroid resistance in the major malaria vector Anopheles funestus. Proc Natl Acad Sci USA. 2013;110:252-7.

19. Crawford JE, Guelbeogo WM, Sanou A, Traoré A, Vernick KD, Sagnon N, et al. De novo transcriptome sequencing in Anopheles funestus using illumina RNA-seq technology. PLoS ONE. 2010;5:e14202.

20. Tchigossou G, Djouaka R, Akoton R, Riveron JM, Irving H, Atoyebi S, et al. Molecular basis of permethrin and DDT resistance in an Anopheles funestus population from Benin. Parasit Vectors. 2018;11:602.

21. Wondji CS, Irving H, Morgan J, Lobo NF, Collins FH, Hunt RH, et al. Two duplicated $\mathrm{P} 450$ genes are associated with pyrethroid resistance in Anopheles funestus, a major malaria vector. Genome Res. 2009;19:452-9.

22. Schmittgen D, Livak J. Analyzing real-time PCR data by the comparative CT method. Nat Protoc. 2008;3:1101-8.

23. Tamura K, Peterson D, Peterson N, Stecher G, Nei M, Kumar S. MEGA5: Molecular evolutionary genetics analysis using maximum likelihood, evolutionary distance, and maximum parsimony methods. Mol Biol Evol. 2011;28:2731-9.

24. Hudson R, Slatkin M, Maddison WP. Estimation of levels of gene flow from DNA sequence data. Genetics. 1992;132:583-9.

25. Ding Y, Hawkes N, Meredith J, Eggleston P, Hemingway J, Ranson H. Characterization of the promoters of Epsilon glutathione transferases in the mosquito Anopheles gambiae and their response to oxidative stress. Biochem J. 2005;387:879-88.

26. Ortelli F, Rossiter LC, Vontas J, Ranson H, Hemingway J. Heterologous expression of four glutathione transferase genes genetically linked to a major insecticide-resistance locus from the malaria vector Anopheles gambiae. Biochem J. 2003;373:957-63. 
27. Lumjuan N, Rajatileka S, Changsom D, Wicheer J, Leelapat P, Prapanthadara $L A$, et al. The role of the Aedes aegypti Epsilon glutathione transferases in conferring resistance to DDT and pyrethroid insecticides. Insect Biochem Mol Biol. 2011;41:203-9.

28. Clarke PJ. Dispersal of grey mangrove (Avicennia marina) propagules in southeastern Australia. Aquat Bot. 1993;45:195-204.

29. Duke NC, Benzie JAH, Goodall JA, Ballment ER. Genetic structure and evolution of species in the mangrove genus Avicennia (Avicenniaceae) in the Indo-West Pacific. Evolution. 1998:52:1612-26.

30. Athrey G, Hodges T, Reddy M, Overgaard HJ, Matias A, Ridl FC, et al. The effective population size of malaria mosquitoes: large impact of vector control. PLoS Genet. 2012;8:e1003097.
31. Mwangangi J, Mbogo C, Orindi B, Muturi E, Midega J, Nzovu J, et al. Shifts in malaria vector species composition and transmission dynamics along the Kenyan coast over the past 20 years. Malar J. 2013;12:13.

\section{Publisher's Note}

Springer Nature remains neutral with regard to jurisdictional claims in published maps and institutional affiliations.
Ready to submit your research? Choose BMC and benefit from:

- fast, convenient online submission

- thorough peer review by experienced researchers in your field

- rapid publication on acceptance

- support for research data, including large and complex data types

- gold Open Access which fosters wider collaboration and increased citations

- maximum visibility for your research: over 100M website views per year

At BMC, research is always in progress.

Learn more biomedcentral.com/submissions 